teristically, the bacilli. I striking resemblance exists between the bacillus of the two diseases. The bacillus of tuberculosis is rather long and somewhat bent; this is not the case with that of leprosy. Some authorities think lepra bacilli stain much easicr than those of tuberculosis, which accounts for the difference; on the other hand, it is claimed this can not be regarded as a distinction. "But the distribution of the bacilli in the tuberculous and leprous tissue is generally so very different, the tubercle bacilli being usually arranged singly, the lepra bacilli always in large quantities in masses and clumps, that a confusion of the two diseases anatomically can only be possible in exceptional cases."

\section{CONJUGAL TUBERCULOSIS. A STUDY OF CASE TO CASE INFECIION.}

\section{H. M. BANNISTLR, M.D.}

eilcago.

The notion of the contagiousness of tuberculosis is largely an a priori conception and not based exclusively on clinical evidence. It is only within the past two decades that it has been seriously considered by the medical profession, certainly in most countries, and until Koch's discovery of the tubercle bacillus it was, if held anywhere, at least a quiescent theory. Nowadays no one can reasonably question the fact of its communicability to a certain extent, since there is ample evidence of the fact of its occasional occurrence. 'The question remains, what is the proportionate danger of such occurrence, and does the incidence of phthisis depend so much on direct infection as on constitutional and hereditary predisposition? There is a tendency, of late very manifest, to magnify the former and correspondingly disparage the influcnce of the latter. and the hereditary clement in the causation of the disorder, bids fair to be repudiated by the profession, or in any case to be comparatively neglected. It appears to the writer, therefore, that it might be worth while to collect what data are available to be at least suggestive as regards this question. If we find that ordinary exposure to tuberculosis is not necessarily or as a rule followed by the disease, it would be a fact well worth noting, and if we also find that heredity seems still strongly in evidence, both facts together would go far to reinstate the formerly held notions of etiology of the disease at the expense of the modern notion of its virulent communicability or contagion. There is some authority still for the opinion that direct transmission of the disorder is rare; Sir H. D. Beevor, ${ }^{1}$ in a recent article, concludes from an analysis of the mortality statistics of certain English districts, that the local constancy of phthisis mortality does not indicate the action of such a disturbing factor as case to case infection. He also quotes other authorities who have noticed the same facts, among them Andvord who, from a careful inquiry into the tuberculous mortality of five Swedish towns for ten to sixteen years, concluded that in like places special constancy of lung tuberculosis points to no place among infectious illnesses, a view that Beevor himself endorses.

It seemed to me, therefore, that if some other possibly more direct statistical proof of this view could be had it would be of some value. An inquiry as to the incidence of lung tuberculosis in a class in which any common heredity could be excluded and in which the possibilities of contagion or direct case to case communication of the disease are at a maximum would apparently best furnish facts bearing on the question.

\footnotetext{
1. British Med. Jour., Aug. 18, 1900.
}

If contact or association could cause the spread of pulmonary tuberculosis, there could be no more favorable conditions found for its transmission than the relations of husband and wife. If one of these is affected it would seem that with the popular teaching as to the contagion of consumption, nothing short of absolute immunity could save the other, the more so since we know that in hardly any case, and in none up to recent years, have there been any special precautions against contagion employed. Therefore, a study of the incidence of tuberculosis in married couples would have some value provided the facts were collected under the proper conditions. The first of these is that any series of cases fairly represents the aggregate experience or obscrvations of the narrator. It is easy to collect exceptional facts that impress themselves upon us, but such are of no value in proving rules; what is wanted is a statement of all cases that conform to certain other requircments of the question. These are that: 1 , there should be no question as to the facts, no conjectures as to diagnosis or other points, and 2 , the observation should have been sufficiently prolonged to avoid the possible cluarge of insufficiency and consequent unreliability. It is easy to obtain accounts of apparent infection from husband to wife and vice versa, especially since the discovery of the tuberculosis germ; almost any general practitioner of long experience can report one or two. It is another thing, however. to obtain records of all the cases in one's observation in which one or the other or both have suffered, and to secure at the same time data meeting the above conditions. I have been able to secure thus far the following thirty-two cases, most of them in my own personal acquaintance, and the facts beyond any doubt as regards requirements stated above.

CASE 1.-B. J., of good family history except that his father died young, probably not of tuberculosis, married M. C., of considerable neurotic and tuberculous taint. Three sons were born; the oldest died of tuberculosis at the age of 20 ; the father died two years later of the same disease, the mother following him a few weeks later, after having been recognized as consumptive for a longer time than her husband. The youngest son died of tuberculosis nineteen years later, and the second son in an epileptic attack still later.

In all of these cases there was no question as to the diagnosis and it seems probable that the husband was infected by the wife, though there was a history of something like a possible lung traumatism that may have had its influence.

CAse 2.-D. J., the youngest son of B. J. and M. C. (see above), married J. L., whose family history so far as known was good, and died of typical tuberculosis some years later, the exciting cause unknown. 'There were no children. His wife, who nursed him through all his illness, did not contract the disease and after twenty or more years is still living in good health.

CASE 3.T. W. whose mother and one sister were supposed to have died of consumption, married M. F., whose family history is unknown. She has survived him twenty-one years, in rood health. Their children are still living. J. W. died in 1880 , of well-marked. typical pulmonary tuberculosis.

CASE 4.-P. C. C., whose family history was unknown, died of typical pulmonary tuberculosis in 1861 . His wife, H. C. C. never showed any signs of the disease, and died in 1900 of ailments incident to old age. Five surviving children are all well.

Case 5.-W. F. J., whose family history was dubious as to ancestral tuberculosis, and with some alcoholism in the ancestry, married M. C., whose family history was supposed to be good. He died of tuberculosis, nearly twenty years before his wife, who died of senile decay at about 80 . Of three children, one daughter died of consumption before her father.

CAsE 6.-F. F., whose father died of organic brain disease, married G. F., who died of tuberculosis within two years of her marriage. Her husluand. who was deroted to her, exhibited 
marked symptoms of the disease and was expected to follow her, but made a good and rapid recovery after her death. He is now, several years later, living and in good health.

CASE 7.-H. F. J., whose mother died at an advanced ageover 60 -probably of tuberculosis, married G. S., whose brother died of tubereulosis, and who followed him herself from the same disease a few years later. Her husband married again, and died suddenly a number of years later from the effects of alcoholism. He was never suspected of being tuberculous.

CASE 8.-R. L. C., a physician of good heredity so far as known, lost his wife by consumption and was himself apparently far gone with the disease at the time. He had severe hemorrhages, but recovered rapidly after his wife's death, and lived many years.

CAse 9.-W. F. C., another physician, lost his wife over six years ago from tuberculosis. While much depressed by his loss, he showed no signs of the disease so far as known. Her father had been consumptive, carried a lung cavity, recovered by change of climate, and died at an advanced age from another cause. W. F. C. is still living and in good health.

CAse 10.-MI. L., whose family history was generally good, died of tuberculosis after a long illness, during which he was carcd for by his wife under conditions not specially favorable. sile kept her health perfectly and is still living, over fifteen year's later.

CASE ll.-H. J. C., whose family history was good, contracted tuberculosis apparently following a rather severe thoracic traumatism. He was constantly nursed by his wife, who was a daughter of M. L. (Case 10), under depressing conditions. At the time of his death she was considerably run down in health, but there was no suspicion of tuberculosis, and she is now, ten year's later, in good health.

CAsE 12.-T. E. W., a cornet player, whose family history was unknown, died eight years ago of tuberculosis, after a long illness. His sputum was full of bacilli for months. He lived in one room, most of the time sharing his bed with his wife, whose health continued perfect. She is now, after seven years, still living and in good health. Her family history is unknown.

CASE 13.-J. A., with a fair family history-somewhat neurotic in the collateral line-died of tuberculosis, the exciting caure unknown. His wife is unaffected, in robust health many years later. Has married again.

CASE 14.-W. K. A., whose family history was good, married 1. M., whose family history was unknown, but supposed to be good. Her death from tuberculosis occurred many years ago; the husband, unaffected, has married again. Two sons are in good health.

CASE 15.-A. B. S., a pharmacist, died after a protracted illness of tuberculosis. He was especially fond of having his children about him during his illness, but neither they nor his wife contracted the disease. All are in good health over six years later.

CASE 16.-W. S., died of tuberculosis after a protracted illness, having been attended by his wife. She continued well and is, I believe, still living after thirty years. Her family history is unknown.

CASE 17.-W. G. C., married C. A., whose family history was unknown. She died of tuberculosis. He is still living and well after many years.

CASE 18.-W. C. R., whose sister was consumptive, died after several years' illness of tuberculosis. His wife, with a good family history, survives him in good health, over seven years.

CASE 19.-A. B., married D. C., whose brother died of phthisis, but who had, as far as direct ancestry was concerned, a good record, both parents living to advanced ige, one dying from carcinoma and the other from apoplexy. The stock, however, was neurotic and tuberculous in collateral branches. She died of phthisis; her husband survived her many years in good health and married again.

CASE 20.-C. J., a first cousin once removed of D. C. (Case 19), died of tuberculosis lasting about a year. His wife is in good health seven years later.

Case 21.-E. G. S., died of tuberculosis. Her husband married again and is living thirty years after his first wife's death.

CASE 22.-P. J. married N. S., whose family history was good. He died of phthisis. The wife is well four years later.

Case 23.-C. E. W., whose family history was good as far as known, died of tuberculosis. His wife is well over two years later.

CASE 24.-A. H. died of tuberculosis, supposed to be started by trauma. His wife remained well, married again, and is still living after many years. One of her family is said to have died of tuberculous meningitis.
Case 25.-W. F. died of phthisis. He married the sister of the wife of $A$. H. (vase 24 ), who died a number of years later from la grippe; no tubereulosis.

CASE 26.-A. V., colored, died of acute tuberculosis. His wife and children are well eight years later.

CASE 27.-R. D., colored, died of phthisis, and his wife is living and well eight years later.

CASE 28.-C. H. died of phthisis. Her husband is living and vell five years later.

CASE 29.-H. A. died of phthisis, and his wife is living and well several years later.

CASE 30.-D. died of phthisis. His wife is well over two years later.

Case 31-C. J., whose family history was good, married A. P., of a tuberculous family - father, mother and one or more brothers and sisters had died of phthisis. A. P. lied of tubereulosis; the only child of the union died young of diphtheria. The husband is well after twenty or more years, and has married again and reared a large family.

CASE 32.-E. F. C., a brother of Case 9, lost lis wife from tuberculosis some ten rears ago, and is still living, with no signs of the disease.

All of the above thirty-two cases were known to me either personally or through the other members of the families, and all meet the conditions stated above. At least half a dozen more might be added, the facts being reasonably certain, but not so absutely assured as in those enumerated. There was some possible uncertainty as to the health of the surviving partner a few years after the others, or the history of the fatal disease, though given as pulmonary tuberculosis, left a possible doubt as to the diagnosis. Some of these cases are interesting as regards the facts of hereditary predisposition, but I have thought best not to use them for the forcgoing reasons. In all of them, however, the freedom of the survivor from pulmonary tuberculosis for several years was assured.

As before stated, it is easy to get isolated cases of apparent infection of husband or wife, but it is hard to obtain any large number of them in the observation of a single individual. It is also easier still to obtain accounts of cases where this did not occur. There is a difficulty, however, in obtaining the aggregate observations of any one physician on this point: and it is a good deal to ask of them that they should take the trouble to recall and record them. Dr. Norman Bridge, of Los Angeles, Cal., has, however, kindly furnished me with the following list of cases which he has been able to collect and rouch for as meeting the conditions of the inquiry:

1. A. W. K.'s wife died of phthisis, and the husband is well nine years later. 2. P. C. B.'s wife died of phthisis, and he died nine years later of Bright's disease. 3. G.'s husband died of phthisis, but she is well five years later. 4. V.'s wife died of phthisis, and he is well eight years after. 5 . T. lost her husband from phthisis, and is well six vears later. 6. E. 5 wife died of phthisis, yet he is well five years later. $7 . \mathrm{N}$. lost her husband from phthisis, and is well seven years later. 8. F.'s wife died of phthisis, and he developed the disease one or two years later and suicided. 9. F. lost his wife from phthisis, and is well six years later. 10. A. lost his, and is well two vears later. 11. W.'s husband died of phthisis, and she is well ten years later. 12. W. also lost her husband therefrom, and is well three years later. 13. J.'s wife died from phthisis, and he is well five years later. 14. F.'s husband died from phthisis, and she is well ten years later. 15. T.'s husband also died from phthisis, and she is well eight years later. 16. F. lost his wife from phthisis, and is well two years iater. 17. M. lost his, and is well four years later. 18. C.'s wife dicd of phthisis, and he is well five years later; has married and buried another wife with phthisis, and is well a year later. 19. B. lost his wife from phthisis, and is well three years afterward. 20. B.'s husband died from phthisis, and she is well seven years later. 21. B.'s died, and she is well ten years later. 22. G. lost her husband from phthisis, and is well ten years afterward. 23. F. lost hers, and is well two years later. 24. S. lost her husband from phthisis, and she is well eiorht years afterward. 25. $\mathrm{X}$. lost her husband, also from phthisis, 
and is well ten years later. 26. 1).'s wife died of phthisis, and he is well two years later. 27. B.'s husband died of phthisis, and she died with the same disease two years later. 28. G. lost his wife from phthisis, and is well nine years later, and remarried. 29. Another lost her husband from phthisis, and is well eight years later. 30. M. Jost hers from phthisis, and is well ten years later, and remarried. 31. 'V.'s husband died from phthisis, and she is well nine years after. 32 . B. lost her husband from phthisis, and she is well four years later. 33. T.'s husband died from phthisis, and she is well nine years later. 34. A dentist lost his wife from phthisis, and he died three years afterward, also from phthisis.

Taking the whole of the above series together, certain interesting facts are at once manifest: 1 . The comparatively small proportion of apparent direct conjugal infection. Out of a total of sixty-six cases we have only five of possible communication from husband to wife, or vice versa, and only three deaths, a proportion of less than one in twenty. This is the more remarkable in that it is far below the ratio of deaths from consumption to the general mortality: which is estimated by some as high as onc in seven, and is probably not less than one in nine or ten at the best. It is true that the majority of the survivors of the pairs above enumerated are not dead yet, and some of them may die of consumption, but the present freedom from the disease does not speak for any actively contagious character of tuberculosis.

Another striking feature is the predominant figure of surviving wives. The wife would naturally be supposed to take more chances of contagion than the husband; she is generally the nurse and close attendant of her suffering partner. Here, however, we find 20 wives surviving their husbands, and only 11 husbands surviving wives (excluding No. 1) in my own series and 18 wives to 16 husbands in Dr. Bridge's, while 2 of the 16 died later of phthisis, and none of the wives. It is true that according to the more recent statistics in Great Britain (Newsholme ${ }^{2}$ ) the percentage of female mortality from tuberculosis is less than that of males, and the decrease of late years has been much more marked in the former, but this would not be sufficient to account for the condition here presented. So far as the facts appear, considering the probable greater exposure of the wives, they do not prove the extreme contagiousness nor communicability of pulmonary tuberculosis.

The cases of possible infection deserve a few remarks. In Case 1, of my own series, it seems probable that the husband was infected by the wife, or by the wife and the son who died before his parents. Here, however: there is the possibility of a lung traumatism having had some etiologic influence. In Case 8 of the same series, the husband was a physician, who for a time, to my personal knowledge, considered his case hopeless, and yet in spite of all the rational symptoms of phthisis, hemorrhages, etc., he made a good recovery. In Case 6 the symptoms were similar and the recovery even more rapid after the death of the wife. Such cases would appear to support the theories of contagion, but emphasize still more the fact of individual resistance; so soon as the influence of active infectious contact was done away with, the constitutional resistance came into play and the patient recovered. Another curious fact which, however, may be only an accident, is that in both series the cases of infection were exclusively from the wife to the husband. So far as it is indicative of anything it supports the other fact already noticed, of the excess of wives surviving husbands as favoring a lesser predisposition on the part of the female.

2. Elements of Vital Statistics, 1899, p. 237.
'There was heredity in ascendants in at least nine of the married couples in my own series of cases, or in about 50 per cent. of those where the family history was known, and in two of these also in descendants. These figures only represent my personal knowledge of the family history, and are not exhaustive. In at least six cases the marriages were childless; in two there was direct ancestral-possible or certain-and in one collateral heredity on the part of the surviving husband or wife.

As already remarked, it is easy to obtain isolated cases of apparent contagion of phthisis, but not a large number from any one physician. Physicians of over thirty or forty years' pracuce in country towns, where practically every case of the disease during all that time came within their personal knowledge, could give only two or three clearly marked cases of conjugal infection from their experience, and only had a general impression that there might be more were the records available. One or two instances have been reported to me that would seem to indicate a special virulence of the infection or a peculiar coincidence of susceptibility or lack of resistance. The following, reported to me by Dr. N. M. Dodson, of Berlin. Wis., is one of this character. A. of healthy family lost his wife from consumption In two or three years he developed the disease himself, but in the meantime had married another wife with no consumptive family taint. She also contracted the discase and her death preceded that of her husband. In another case, reported to me by Dr. George H. Simmons, of Chicago, a mother attended her married daughter who died of phthisis, contracted the disease herself: apparently communicated it to her husband and one or more of her children, all dying. In this case, however, there would appear to be a family tendency, possibly on both sides, rendering them particularly liable to the infection.

Though sixty-six cases are but a limited material from which to draw conclusions, yet the fact that they represent the full experience of two observers make the data worthy of consideration. I regret that I could not obtain the experience of other physicians, but 1 do not feel like blaming a busy practitioner for not caring to take the trouble to go over his notes and recollections, and to verify them; it is a task, as I myself discovered. The facts as given are at least suggestive and, so far as they go, indicate a much greater risk so far as personal danger of acquiring tuberculosis is concerned from having a phthisical parent than from having a tuberculous husband or wife.

\section{KELOID FOLLOWING TRAUMA'TISM.* \\ W. M. COLE, M.D. \\ rotembus, outo.}

Keloid, a term first applied by Alibert in the year 1814 , to a pathologic condition known as an overgrowth of scar tissue, was so named by reason of its resemblance to a crab. The term is also applied to apparent fibrous outgrowths of the skin of a similar character, formerly believeed to be of spontaneous origin, but now the theory is accepted that they are results of lesions in the skin. This is said by some authors to be a somewhat rare disease and affects the colored races more than the white. It is commonest in middle age, but may occur in any age of life. Its favorite sites are the anterior superior sternal region, the shoulders and the neck, but may occur on any part of the body.

* Read at the Annual Meeting of the American Academy of Railway Surgeons, held at St. Paul, Minn., Sept. 5 and 6, 1900. 